\title{
L'exposition «E Tū Ake » (Maori debout) à Wellington, Paris et Québec. Affirmation culturelle et politiques du patrimoine
}

The "«E Tū Ake» (Standing Strong)" exhibition in Wellington, Paris and Québec. Cultural assertion and heritage policy

\section{Gaëlle Crenn et Mélanie Roustan}

\section{OpenEdition \\ Journals}

Édition électronique

URL : http://journals.openedition.org/iss/407

DOI : $10.4000 /$ iss. 407

ISSN : 2306-4161

Éditeur

ICOM - International Council of Museums

\section{Édition imprimée}

Date de publication : 1 décembre 2015

Pagination : 71-85

ISSN : 2309-1290

\section{Référence électronique}

Gaëlle Crenn et Mélanie Roustan, «L'exposition «E Tū Ake » (Maori debout) à Wellington, Paris et Québec. Affirmation culturelle et politiques du patrimoine », ICOFOM Study Series [En ligne], 43b | 2015, mis en ligne le 06 février 2018, consulté le 21 décembre 2020. URL : http://journals.openedition.org/ iss/407 ; DOl : https://doi.org/10.4000/iss.407 


\title{
L'exposition « E Tū Ake » (Maori debout) à Wellington, Paris et Québec. Affirmation culturelle et politiques du patrimoine
}

\author{
Gaëlle Crenn \\ Université de Lorraine - France \\ Mélanie Roustan \\ Muséum national d'histoire naturelle - France
}

L'exposition "E Tū Ake (Standing Strong) » a été conçue par le musée Te Papa Tongarewa (Wellington, Nouvelle-Zélande, 2011), puis proposée au Musée du Quai Branly (Paris, France, 2011-2012) et au Musée de la Civilisation du Québec (Québec, Canada, 20122013). Elle se veut un autoportrait des Maori. Elle donne à voir des éléments des collections du musée Te Papa Tongarewa présentés comme des "trésors culturels ", en articulant artefacts anciens et contemporains à un propos centré sur la persistance culturelle, l'affirmation identitaire et les revendications politiques. Si les objets et le découpage conceptuel de l'exposition demeuraient inchangés entre Wellington, Paris et Québec, les scénographies étaient fort différentes - et, bien entendu, les contextes institutionnels autant que les cadres de la réception. Dans ces trois contextes, nous avons étudié les objets exposés et leur scénographie, et mené une double enquête de terrain : auprès des équipes des institutions et auprès des visiteurs. Nous cherchons à comprendre comment, dans la circulation de l'exposition, sont produites, négociées et contestées des conceptions du monde matériel et des représentations de la culture maori ${ }^{23}$.

La recherche s'inscrit dans le courant de la muséologie « critique et comparative » telle que définie par Christina Kreps: l'étude systématique des similarités et des différences dans les formes et les comportements muséologiques en situation interculturelle (Kreps, 2003 , p. 4). Cette approche peut être vue, selon l'auteure, comme l'un des nombreux acquis de la critique postcoloniale des musées et des pratiques muséales :

\begin{abstract}
II n'est plus possible de considérer le concept de musée et les pratiques curatoriales occidentales comme des donnés naturels, mais nous devons aujourd'hui les voir comme des artefacts culturels en tant que tels, ou des produits de contextes historiques et culturels particuliers créés pour servir des intérêts et des objectifs spécifiques. Cette approche plus critique et plus réflexive a éclairé comment les positions curatoriales d'autorité et de pouvoir peuvent donner forme aux pratiques muséologiques (Kreps, 2011, p. 459).
\end{abstract}

A travers l'étude de l'exposition "E Tū Ake », nous interrogeons la notion de musée comme "zone de contact » élaborée par James Clifford. S'inspirant de Marie-Louise Pratt, Clifford considère le musée

\footnotetext{
${ }^{23}$ Cette recherche comparative est menée en coopération avec Lee Davidson, de l'université Victoria de Wellington, et Natacha Gagné, de l'université Laval à Québec. Le projet a bénéficié du soutien des différentes institutions de rattachement de l'équipe, ainsi que d'une subvention du ministère français de la Culture et de la Communication. Nous tenons également à remercier le musée Te Papa Tongarewa, le musée du quai Branly et le musée de la Civilisation du Québec pour leur coopération.
} 
comme « un lieu où des cultures et des communautés différentes se croisent, interagissent, et sont mutuellement influencées par la rencontre » (1997, p. 192). Comme le commente Conal McCarthy,

\begin{abstract}
Malgré des conflits inévitables dans des situations de pouvoir asymétriques, Clifford montre comment ces relations peuvent être productives, [quand] des cultures " traditionnelles nouvelles » ont été réinventées à partir des ressources du musée. Dans les états "post-settlers », cet engagement mutuel est encore plus marqué parce que les peuples autochtones ne sont pas éloignés dans le temps et dans l'espace, " loin là-bas, et dans le temps » comme on le disait, mais bien présents ici et maintenant. (McCarthy, 2011, p. 5)
\end{abstract}

La pertinence du recours à la notion de "zone de contact " a été largement commentée dans le champ des études muséales. Pour certains détracteurs, elle reste insuffisante pour rendre compte des relations de pouvoirs installées, car elle n'est elle-même qu'un artefact des programmes de gouvernementalité (governementality) des musées (Bennett, 1998, 2006) et contribue plutôt à euphémiser les effets de la domination subie, notamment par les autochtones, dans leurs rapports aux musées (Onciul, 2012). D'autres auteurs considèrent qu'elle permet d'éclairer les relations changeantes que les musées entretiennent avec leurs "communautés sources" (Peers \& Brown, 2003) et de rendre compte des transformations en cours dans les relations interculturelles (Witcomb, 2003).

Notre démarche entend contribuer au débat. Elle se situe à la jonction d'une approche communicationnelle des expositions et de leur réception (Crenn, 2003, 2012) et d'une anthropologie du musée du point de vue de ses usages (Debary \& Roustan, 2012 ; Monjaret \& Roustan, 2013; Roustan, 2014a, 2014b). À travers l'étude de l'exposition dans ses trois occurrences, nous explorons la façon dont les conceptions du patrimoine sont produites et négociées au sein des musées et entre eux. Notre démarche s'appuie sur l'analyse scénographique des expositions et celle de leur accueil dans les musées hôtes, en tenant compte de la posture énonciative des partenaires institutionnels et des stratégies de communication privilégiées. Nous nous appuyons également sur les entretiens réalisés avec les professionnels des musées (en conservation, en médiation et en communication) ayant été impliqués dans les mises en place de l'itinérance ${ }^{24}$. Quelles sont les conceptions des objets et du patrimoine qui sont discutées et négociées au cours de la circulation de l'exposition, en fonction de ses conditions d'accueil dans le musée hôte et de ses pratiques muséographiques? Quels sont les usages du patrimoine qui prévalent, en fonction des contextes institutionnels et des politiques muséales concernant l'autochtonie? Quels effets la circulation des collections maori engendre-t-elle? Après une présentation de l'exposition, nous abordons dans un premier temps le message implicite porté par le choix des objets opéré pour l'exposition. Puis nous détaillons la façon dont ils sont présentés et scénographiés dans les trois contextes. Enfin, nous présentons des éléments de métadiscours produits par les musées autour de l'exposition, relevant les différents registres employés qui permettent d'éclairer les positionnements de chaque institution. Cette analyse met au jour les conceptions du patrimoine matériel et immatériel que la sélection de taonga véhicule, et montre

\footnotetext{
${ }^{24}$ Les entretiens auprès des visiteurs ne sont pas mobilisés dans ce texte. Pour une analyse comparée des réceptions de l'exposition à Paris et à Québec (Gagné \& Roustan, 2014).
} 
comment les conceptions du patrimoine propres aux différents musées sont négociées lors de l'accueil et de la mise en place de l'exposition.

\section{Une exposition "clef en main », typique et exemplaire du savoir-faire du musée Te Papa Tongarewa}

L'exposition «E Tū Ake (Standing Strong) » résulte de l'adaptation d'une exposition antérieure, intitulée "Mauri Ora: Trésors maori du Musée National de Nouvelle-Zélande Te Papa Tongarewa », présentée au Japon en 2007. Au musée Te Papa Tongarewa, l'idée a germé de retravailler cette exposition en vue d'une tournée internationale. On peut penser qu'a pu peser dans cette décision le précédent qu'a constitué au milieu des années 1980 la tournée de l'exposition «Te Maori » (notamment au Metropolitan Museum à New York), événement considéré comme un tournant dans la reconnaissance internationale de la Nouvelle-Zélande en général et de la culture maori en particulier (McCarthy, 2011). Inauguré en 1998, le musée national Te Papa Tongarewa (Museum of New Zealand Te Papa Tongarewa), situé dans la capitale, à Wellington, est un musée biculturel, lieu d'affirmation du récit national de Aotearea-NouvelleZélande. Très populaire, familièrement appelé "Our place », le musée est un des espaces de reconnaissance et d'affirmation des Maori comme membres fondateurs à part entière de la nation néozélandaise. Les différentes parties du musée permettent de raconter le récit national selon plusieurs perspectives, qui tantôt coexistent et tantôt s'intègrent partiellement: celle des Néo-Zélandais d'ascendance européenne, descendants des colons pionniers (appelés en langue maori les Pakeha), celle des Maori, celle des habitants du Pacifique. Le musée Te Papa Tongarewa se distingue par une organisation et des pratiques professionnelles caractéristiques de la muséologie participative: des leaders maori sont associés à titre d'experts aux plus hauts niveaux de décision. Parmi le personnel de conservation, des gardiens maori effectuent les rites nécessaires pour traiter correctement les taonga présents dans le musée. II s'agit d'assurer leur bonne préservation, non seulement physique mais également spirituelle: de garantir le maintien de leur force vitale (mauri). L'exposition « $E$ Tū Ake » a été conçue et produite par un groupe de pilotage (steering group) composé majoritairement de Maori travaillant au musée et de leaders de tribus (iwi) qui ont été consultés. Considérée comme une exposition "clef en mains ", conçue avant tout pour une itinérance étrangère, son montage a été à chaque fois supervisé par une délégation maori.

Le propos de l'exposition est centré sur la persistance culturelle, l'affirmation identitaire et les revendications politiques. Concernant la perspective énonciative, l'exposition est présentée d'emblée comme exprimant "un point de vue maori contemporain », dressant un tableau de «la culture vivante et dynamique des Maori, le peuple autochtone de Aotearoa-Nouvelle-Zélande " (Catalogue, version anglaise, Introduction, p. 12 - notre traduction), et de ses aspirations. Selon la commissaire et auteure du catalogue Huhanah $\mathrm{Smith}^{25}$, elle a pour thème majeur "la quête de l'autodétermination des Maori " (Catalogue, préface, p. 10). Elle est de plus « faite par les Maori euxmêmes », qui s'expriment sur ce qu'est leur culture. On peut noter

\footnotetext{
${ }^{25}$ Huhana Smith a été ensuite remplacée par Ronda Paku.
} 
que cette perspective est éloignée d'une approche du dialogue des cultures, telle que la défend le musée du quai Branly.

L'exposition présente des objets anciens (deux tiers de taonga) et contemporains.

\begin{abstract}
[Elle] vise à faire la démonstration qu'il existe une relation vivante entre les taonga, les œuvres contemporaines et les gens qui y sont associés. Les visiteurs expérimentent la beauté et le pouvoir des œuvres taonga en passant devant une sélection d'œuvres contemporaines, avec les forces qui en émanent; dans ce contexte les visiteurs acquerront une compréhension des concepts centraux, des problèmes et des débats pertinents pour les Māori aujourd'hui. (musée Te Papa Tongarewa, document Concept).
\end{abstract}

Cette perspective correspond au positionnement muséal du Te Papa Tongarewa, dont l'exposition « $E$ Tū Ake » constitue une réalisation à la fois typique et exemplaire. C'est une réalisation typique par cette volonté d'activation de la puissance des œuvres. L'expérience esthétique du visiteur est censée l'amener à expérimenter les visions du monde et les principes régissant la culture des Maori, et le faire ainsi accéder à une compréhension de leurs aspirations collectives contemporaines. C'est une réalisation exemplaire en tant qu'elle est conçue pour des audiences internationale ${ }^{26}$ comme une vitrine de la culture maori. Elle est exemplaire enfin au sens où, si l'exposition ambitionne de montrer au monde la culture maori comme composante essentielle de la nation néo-zélandaise, c'est en tant que peuple autochtone que les Maori sont avant tout présentés. Ils font figure d'exemple de peuple parvenant à lutter pour régénérer, revivifier une culture pourtant parfois très menacée, dont la langue passe «du statut d'être au bord de l'extinction au statut d'être couramment utilisée " (Catalogue, Introduction), et de modèle, apportant des solutions possibles aux autres peuples autochtones rencontrant des problèmes similaires.

Le parcours conceptuel de l'exposition est fondé sur la notion centrale de tino rangatiratanga, " contrôle de toutes choses maori par les Maori eux-mêmes ", dont "des expressions variées (...) sont illustrées pour éclairer les aspirations des Maori » (musée Te Papa Tongarewa, document Concept). Trois aspects sont principalement déclinés, articulant le parcours de l'exposition autour des concepts maori suivants :

1. Whakapapa: «système de référence généalogique, identité culturelle $»^{27}$

2. Mana: "intégrité, charisme - qualités souvent associées au leadership ${ }^{28}$

3. Kaitiakitanga : « responsabilité de garde, de protection, de bonne gestion de l'environnement naturel ${ }^{29}$.

Dans chaque section, sont explorées des dimensions passées et actuelles des thèmes, en faisant référence à des controverses et des débats. Une partie introductive associe des panneaux explicatifs, apportant des repères historiques, sociaux et politiques, et des

\footnotetext{
${ }^{26}$ Pour ce faire, l'itinérance est envisagée pour un temps assez long, soit un minimum de quinze mois de circulation pour les expositions de Wellington, Paris et Québec (musée Te Papa Tongarewa, document Concept).

${ }^{27}$ Identity and interconnectedness (titre de section dans le catalogue et dans les textes d'exposition, version originale anglaise).

${ }^{28}$ Empowerment and leadership.

${ }^{29}$ Protection and sustainability; guardianship; stewardship.
} 
vitrines présentant des objets emblématiques, un taonga introduisant chacun des trois concepts structurant le parcours. Dans sa version originale au musée Te Papa Tongarewa, l'exposition est montée dans la galerie Visa Platinum, dédiée aux expositions temporaires une galerie de prestige, située au cœur du musée et accessible en entrée libre. L'exposition est présentée aux publics néo-zélandais comme le médium d'une reconnaissance de l'intégration des Maori dans la nation et de la légitimité de leur affirmation culturelle et politique. En termes de fréquentation, un public maori plus important qu'à l'accoutumée est attendu pour cette exposition, ouverte durant la période creuse automnale (avril-juin) dans une galerie où la surreprésentation des publics d'origine européenne est habituellement marquée (musée Te Papa Tongarewa, Audience Statement).

\section{Des objets inscrits dans un double paradigme patrimonial, autochtone et international}

Quels objets ont été choisis pour représenter la culture maori ? La sélection des pièces exposées est révélatrice du propos de l'exposition. Les objets présents (et, en creux, les objets absents) dégagent un discours implicite qui inscrit l'exposition au sein d'un univers de référence, notamment en termes de présupposés liés au « genre » de celle-ci, à la catégorie au sein de laquelle elle s'attache à exister. Ils disent ce qu'elle entend être et ce qu'elle se défend d'être.

Des objets de différentes époques, entre ethnographie et histoire Parmi les objets choisis pour être montrés, se trouvent des objets anciens, datant de plusieurs siècles, et des objets contemporains. Par exemple, une pirogue (waka) contemporaine high-tech, avec une vidéo d'une course sportive récente la mettant en scène, côtoie la poupe (taurapa) d'un célèbre waka du nom de Kahutiaterangi, encore en usage en 1830. La juxtaposition suggère l'idée de continuité culturelle, d'absence de rupture dans les techniques et les styles (la similarité des ornementations est soulignée), alors même qu'il existe des creux dans la transmission de la tradition, des redécouvertes, des renouveaux. La coprésence d'objets de différentes époques implique l'idée de vitalité culturelle, d'une culture vivante ancrée dans le temps long mais capable d'un maintien et d'un renouvellement des pratiques techniques et « artistiques ».

Mais cet assemblage de l'ancien et du contemporain indique surtout ce que l'exposition n'est pas :

- elle ne développe pas une vision passéiste, évolutionniste ou primitiviste, qui présenterait les «traces » d'un peuple, d'une culture ou d'un art disparu ou en voie de disparition ;

- elle ne présente pas une vision ethnographique ou sociologique sur les modes de vie traditionnels ou contemporains des Maori, avec des informations objectives ou objectivées par la science, telles que des données démographiques ou économiques... ou un regard critique sur la place relative des Maori dans la société néo-zélandaise, la question de leur définition politique et juridique ou du métissage ;

- elle ne propose pas de mise à distance de la culture Maori, ne porte pas un " regard sur " mais délivre une vision " de l'intérieur », qui invite à penser et éprouver la temporalité maori (qui fait face au passé, quand le futur est situé derrière). 
De nombreux objets exposés pourraient faire l'objet d'un classement spontané au sein d'une "collection ethnographique »: une table et des chaises, une flûte, un hameçon, une aiguille de tatouage, une photo de famille... Ces objets paraissent liés à des pratiques usuelles et non à un auteur identifié. Les archives, photographies et souvenirs se rattachent aux luttes politiques menées par les Maori, et pourraient être considérés comme "collection historique ». Mais il s'agit d'une histoire en train de se faire, qui arrive jusqu'au présent. Et ces objets apparaissent détenteurs d'une force intrinsèque : "Objets symboles iconiques plus que objets témoins » d'après le catalogue d'exposition (version française). Ils incarnent les combats plus qu'ils ne les relatent. De nombreuses photographies documentent la lutte et tout à la fois sont signées de photographes présentés comme artistes. Deux registres de rhétorique culturelle sont alors mobilisés: l'idée de culture vivante, vécue, vue de l'intérieur, l'idée de culture plus classique, légitimée par l'art.

\section{Des œuvres d'art contemporain}

Parmi les objets présentés, il semble qu'un consensus existe autour d'une série d'objets, pour les considérer comme des œuvres d'art contemporain : ils sont identifiés comme tels par leurs producteurs (des artistes individuels qui se présentent comme tels), leurs intermédiaires (par exemple des galeristes), leurs « metteurs en scène " au sein de l'exposition (les cartels sont sur le modèle de l'art contemporain) ainsi que leurs récepteurs (ces objets laissent peu de doutes aux publics quant à leur « identité »).

Il y a d'abord, là aussi, l'idée d'une vitalité culturelle. La présence de la culture maori sur une scène internationale aussi légitime que celle de l'art contemporain en constitue une " preuve ». Elle montre aussi une appropriation de la notion d'art dans son acception occidentale et un usage de cette catégorie comme levier d'une reconnaissance culturelle fondée sur des critères de créativité, de réflexivité et d'universalité.

Les œuvres d'art contemporain de l'exposition « $E$ Tū Ake » révèlent une réflexivité individuelle sur l'appartenance culturelle, mais il est remarquable qu'elles le fassent toujours en lien avec le collectif, sans critique ou remise en cause de la communauté. La sélection exposée ne comporte pas d'œuvre rejetant la culture maori ou la mettant à distance, par exemple en exprimant l'idée d'un déchirement, d'un exil intérieur, d'une étrangeté à soi-même ou d'un tiraillement entre deux cultures (comme par exemple dans la collection d'art contemporain du musée de l'Histoire de l'immigration, au Palais de la Porte Dorée, à Paris). Les œuvres comportent certes des messages à caractère universel : affirmation des femmes, respect de l'environnement, droit des peuples à l'autodétermination... mais elles puisent dans un répertoire formel et conceptuel de productions traditionnelles. On observe une continuité stylistique dans les ornementations, un jeu récurrent sur les motifs et formes traditionnelles qui sont elles-mêmes conceptuelles, comme les hei tiki ou la représentation cartographique de la cosmogonie. Ces liens révèlent une articulation forte entre patrimoine, territoire et généalogie - propre à la culture māori.

Les œuvres d'art contemporain choisies pour figurer dans l'exposition procèdent d'un double jeu sur la notion d'art: sur le caractère " universel » de l'art (c'est-à-dire dominé par la vision occidentale), dans ses formes (tableaux, photographies) et dans ses thèmes (lutte pour les droits de l'humain) et sur le caractère particulier de l'art (spécifique culturellement) dans ses formes (motifs) et dans ses thèmes (cosmogonie). 


\section{Des taonga encore vivants?}

L'exposition est conçue et présentée, dans son versant matériel, comme une occasion de présenter au public les taonga, les trésors culturels maori - le versant conceptuel étant plus politique, centré sur le droit et la lutte pour l'autodétermination. Peu d'éléments exposés sont exclus de cette catégorie des taonga qui englobe, d'après le catalogue d'exposition, " les expressions - tangibles ou non - de la culture maori ». Les taonga sont ainsi à la fois l'objet matériel, la technique associée, le résultat, le concept...

Les objets choisis pour être présentés s'inscrivent dans un double paradigme patrimonial: d'une part, une vision autochtone du patrimoine où le passé vit dans le présent, où la frontière n'existe pas entre matériel et immatériel, où les hommes sont reliés entre eux et à un ensemble plus large, d'autre part, une vision plus internationale, qui trouve son expression dans la forme de l'exposition et en amont dans la légitimation artistique ou la conservation muséale. Ici, les pièces choisies sont des objets d'art ou de patrimoine, reconnus comme tels ; ils sont plus que cela puisqu'ils sont encore "vivants" et "actifs » - par opposition à l'imaginaire mortifère associé classiquement à l'objet de musée. Ces objets résistent à la neutralisation patrimoniale, en superposant à la reconnaissance artistique le maintien des croyances. Cela se joue dans la sélection des objets donnés à voir, mais aussi dans la façon de les donner à voir.

\section{Les scénographies, entre dramatisation des espaces et intimité du rapport aux objets}

Concernant la scénographie et le design, nos observations ont porté sur le mobilier, tel que les socles et les vitrines, qui cadrent la perception et prescrivent plus ou moins fortement le regard porté aux objets. A été prise en compte la disposition des objets, des fonds et des éclairages. Ont notamment été comparés, entre les trois occurrences de l'exposition, les positions dans l'espace, les relations de proximité ou d'éloignement entre les objets et les manières de les faire "dialoguer", ainsi que ce que cela suppose de "la relation entre traitement de l'espace et expérience du visiteur » (Davallon, 2011, p. 40).

\section{Arbitrer entre esthétique et usage culturel}

Quel que soit le musée hôte, l'exposition «E Tū Ake » présente les objets en fonction de leur usage. Ainsi, un entonnoir qui sert à se nourrir après un tatouage des lèvres apparaît dans le sens de son utilisation: en position horizontale, la partie ouverte destinée à recevoir la nourriture vers le haut. Cette disposition se distingue de celle, adoptée dans la galerie permanente du musée du quai Branly, appelée Plateau des collections, où un entonnoir similaire est présenté de façon verticale avec le fond placé vers le visiteur, disposition qui favorise la vue des gravures sur la partie inférieure. Le critère esthétique, selon lequel l'objet est considéré avant tout comme œuvre d'art, est ici privilégié. Si la présentation utilitaire, où l'entonnoir est présenté dans le sens de l'usage, est aussi adoptée au musée Te Papa Tongarewa, dans l'exposition permanente « Mana Whenua » consacrée aux Māori, c'est cependant uniquement en compagnie d'autres taonga traditionnels. Dans «E Tū Ake », la coprésence d'objets plus techniques (aiguilles de tatoueur) et de témoignages (vidéos de personnes maori tatouées) souligne la 
signification sociale du tatouage, reconnaissance des mérites individuels et de filiation spirituelle avec les ascendants, et la tradition culturelle de cet art. Cette mise en exposition complexifie ainsi la présentation du Ta moko, art du tatouage, taonga à la fois matériel et immatériel, dont le statut, saisi habituellement au musée du quai Branly principalement comme " art», à travers une manifestation matérielle, est mis en question.

\section{Gérer la dimension sacrée}

Dans la conception et l'itinérance de l'exposition "E Tū Ake ", la disposition et la manipulation des objets sont régies par leur caractère plus ou moins sacré. Au cours de l'installation, l'équipe de supervision maori a accompagné les équipes locales afin que les soins adéquats soient apportés: respect de certains tabous en présence des objets, rituels à accomplir avant leur mise en place. La scénographie indique le caractère précieux et " habité » des taonga. La répartition spatiale de ces objets traduit un respect et donne à la visite une solennité, qui est plus affirmée au musée Te Papa Tongarewa que dans les autres présentations. Ces différences sont sensibles lorsque l'on compare par exemple, entre Wellington et Paris, l'ordre de l'emplacement et le mode de présentation de deux objets dans la séquence d'introduction: le canot cénotaphe et le masque funéraire de Wiremu Te Manewha. À Wellington, le canot cénotaphe de bois sculpté fait partie des seuils symboliques qui guident le visiteur, depuis la pierre de jade (pounamou) qu'il est invité à toucher (rite de purification et d'échange des forces), la vidéo introductive (montage qui insiste sur la transmission intergénérationnelle de la culture) et la présentation des trois trésors culturels dans les vitrines centrales (illustrant les trois concepts principaux de généalogie, de prestige et de conservation de l'environnement). Le cénotaphe enfin, met en contact avec le passé (car c'est un mémorial) et impose le respect dû aux ascendants ${ }^{30}$. Comme au musée Te Papa Tongarewa, il fait office de seuil et de sas pour entrer dans le monde de l'exposition, où sont en contact les vivants et leurs ancêtres. Lui fait suite la découverte du masque funéraire d'un chef respecté, Wiremu Te Manewha, masque de plâtre sur lequel les tatouages témoignant du prestige du chef ont été reportés. Le masque est posé à plat sur un plan de vitrine pupitre, à fond blanc. Les photos de descendants dans leurs maisons encadrent la vitrine, et une grande photographie en frise sur le mur blanc adjacent les montre tous rassemblés. La disposition permet de faire le lien entre les objets et augmente le respect ressenti envers l'un et l'autre, en allant de l'un à l'autre.

À Paris, la séquence se trouve modifiée et donne une présentation à la fois plus dramatique et moins axée sur le solennel. La mise en scène dramatique du masque ouvre l'exposition. Isolé et mis en majesté par la vitrine où il est exposé, orienté de biais vers les visiteurs, son pouvoir expressif est rendu impressionnant par un éclairage au pinceau très finement dirigé, qui le fait ressortir très vivement sur le fond noir. Au premier abord, sa véritable nature n'est pas évidente et prête à confusion. Certains visiteurs ont des mouvements de recul ou de gêne. On découvre seulement après, et un peu plus à distance, les photos des descendants, sur une cloison de fond noir. C'est seulement dans la seconde section de l'exposition que l'on découvre le portail, appliqué contre le mur près de la maison de réunion (marae). Appuyé sur le fond blanc de l'espace

\footnotetext{
${ }^{30}$ Le même dispositif est observable pour le portail dans le hall d'accueil du musée $\mathrm{Te}$ Papa Tongarewa.
} 
d'exposition, il est moins impressionnant car, comme on le contemple de plus loin, la perception de la dimension monumentale est moins forte. Selon les présentations, le ressenti de la dimension solennelle et de la filiation avec les ascendants peut ainsi varier, ainsi que les significations construites par les visiteurs.

\section{De l'influence du design sur l'ambiance}

L'ambiance générale sobre produite par le design et la scénographie s'accorde à Wellington avec le respect que sont censés inspirer les objets. L'espace de l'exposition est un " white cube », qui tend par un espace dépouillé et à la neutralisation des fonds à produire une atmosphère solennelle. À Paris, le blanc domine également, dans la galerie jardin, dans une disposition globalement plus aérée, rappelant les expositions d'art contemporain. À Québec, à l'inverse, le noir domine, dans une présentation plus resserrée, qui donne une impression d'intimité plus prononcée. Est ici favorisée l'expérience intime d'œuvres impressionnantes, porteuses de force, qui sont les expressions esthétiques d'une culture.

Concernant la disposition spatiale et le type de présentation des objets dans les différentes sections de l'exposition, des adaptations ont eu lieu, résultant de l'intervention des personnels des musées d'accueil et des scénographes. Le scénographe parisien, propose, lors de sa visite à Wellington, d'éclairer l'ensemble des sections, à Paris, par des projections lumineuses de motifs de tatouages. L'idée produit un choc d'incompréhension de l'équipe (des Māori et des Pakeha) de Wellington, car les tatouages ont une signification spirituelle pour les porteurs et leur création est réservée aux experts. Un compromis est établi pour créer des motifs à partir de modèles transmis par le musée Te Papa Tongarewa. Finalement, dans les projections formant une résille d'ombres, les motifs évoquent plutôt des moucharabiehs. L'ensemble produit, dans l'espace un peu trop vaste de la galerie jardin, une lumière plus douce, où les motifs se reflètent dans les vitrines qui jouent comme des miroirs des œuvres. Dans la partie centrale de l'exposition, l'intervention de la chargée de production, Magali Mélandri, qui s'est vu attribuer, en tant que responsable des collections océaniennes, le rôle de "conseillère » locale, conduit à modifier la scénographie : afin de rendre sensible le caractère sacré des taonga, il est proposé de resserrer les zones de passage dans la section de présentation des capes et des hei tiki : la réduction des espaces de circulation permet un contact plus intime, qui exhausse la beauté et la force qui émanent de ces objets précieux, ce qui est d'ailleurs ressenti par quelques visiteurs.

Au-delà de ces choix de design, la scénographie reste en définitive marquée par les signatures stylistiques propres aux trois musées, qui impriment leur marque distinctive. On peut l'observer dans la comparaison du traitement scénographique des poupou, panneaux sculptés encadrant les entrées de maisons de réunion. Dans la section de l'exposition à Wellington, les poupou font face à la maison de réunion et s'alignent devant une cloison coupée à mi-hauteur, où ils sont simplement posés sur un socle. Sur la cloison perpendiculaire, se trouvent des photos des marae et, dans la continuité du couloir qui se forme, la section dédiée au Ta moko : par cette disposition, les poupou prennent la signification d'éléments d'architecture, typiques, fortement porteurs de significations symboliques (généalogiques, culturelles, mythiques...), mais appartenant néanmoins à l'ordre domestique du proche, du quotidien, de l'habiter. Comme d'autres dimensions de la vie quotidienne proche (la course de canot, le tatouage), ces objets témoins illustrent 
l'intégration des valeurs spirituelles portées par les taonga dans le quotidien des Maori. À Paris, les poupou sont également présentés sur un socle blanc dans un alignement sobre; ils sont cependant placés devant des colonnes qui montent jusqu'au plafond et sont éclairés par des lampes placées au sol. L'éclairage en contreplongée souligne les détails gravés et accentue la force expressive des panneaux : c'est là un traitement plus formel, commun à celui qui est mis à l'œuvre notamment sur le Plateau des collections. À Québec, l'obscurité prononcée de l'environnement, un jeu d'éclairage centré sur les œuvres et la neutralisation des fonds par l'emploi de couleurs sombres, qui tend à faire disparaître les contours du lieu d'installation, donnent aux visiteurs une sensation d'objets flottants. Cet aménagement fait des poupou des œuvres expressives particulières à une culture ; il révèle les forces à l'œuvre dans les objets, forces reconnues comme significatives de la culture du peuple ainsi évoqué, à l'image de ce que l'on peut voir par ailleurs dans les diverses expositions produites par le musée.

\section{Les métadiscours institutionnels, révélateurs des interprétations locales de l'exposition}

Le discours implicite de l'exposition se déploie autour et au-delà de l'espace d'exposition à proprement parler. II s'ancre dans un contexte institutionnel qui inclut des discours officiels et officieux, explicites et implicites.

Nous avons choisi ici de tirer des exemples issus de trois registres différents :

- les musées en eux-mêmes, ce qu'ils expriment de façon diffuse, par leur histoire, leur architecture, leur politique, leur programme d'exposition, leur " style », etc. ;

- les campagnes de communication déployées autour de l'exposition, ce qu'elles disent par le choix des visuels, du graphisme, des termes employés... et des contenus sélectionnés ;

- les propos des professionnels, recueillis lors de l'enquête, où s'expriment à la fois des individus, des cultures professionnelles et des institutions.

\section{Les musées comme contextes}

Trois musées servent de contextes successifs à l'exposition.

Le musée Te Papa Tongarewa est un musée national mais biculturel, connu comme musée participatif ouvert aux communautés et aux rituels liés aux objets conservés. II a pour principe de prendre au sérieux et de favoriser les croyances traditionnelles et ne se situe pas, en ce sens, parmi les établissements qui déconstruisent ou mettent à distance les significations associées aux collections. II joue un rôle de reconnaissance culturelle et politique des Maori, mais également de cohésion sociale à l'échelle du pays, tout en valorisant l'art comme catégorie transversale, voire universelle.

Le musée du quai Branly est un musée national français, dédié aux cultures extra-européennes, qui se place dans une posture d'intérêt pour les productions matérielles de l'« Autre » et prône le « dialogue des cultures ». II est associé dans la culture populaire et les médias à la catégorie d' " arts premiers », issus d'un "tournant esthétique » opéré sur des collections " ethnographiques » et qui a donné lieu à controverse dans le milieu académique. Il se situe officiellement à la 
jonction entre histoire de l'art et anthropologie, avec une politique scientifique de soutien et d'animation de la recherche et de l'enseignement supérieur dans ces disciplines, et une programmation culturelle tournés vers les « cultures du monde ».

Le musée de la Civilisation du Québec est un établissement qui s'attache à l'histoire et aux cultures du Québec, tout en s'élargissant à d'autres civilisations, contemporaines ou disparues. II développe une vision multiculturelle marquée par une politique participative, notamment envers les " premières nations ». II fait preuve d'un intérêt affiché pour la problématique autochtone, dans le cadre de la programmation de ses expositions, mais également dans son fonctionnement en tant qu'organisation.

\section{Les affiches}

Aux trois musées, ont correspondu trois métadiscours sur l'exposition, notamment en termes de supports de communication. L'exemple des affiches de l'exposition est à ce titre frappant.

Au musée Te Papa Tongarewa, l'affiche est une photographie d'une foule manifestant. La photographie, documentaire, donne un gage de "vérité " historique ; elle entretient avec la réalité un rapport de reproduction fidèle. La photographie est en couleurs, ce qui laisse supposer que l'événement immortalisé est relativement récent. La présence de drapeaux apporte une dimension politique au propos. Les langues utilisées sont le maori et l'anglais, soulignant la dimension biculturelle de la Nouvelle-Zélande et redoublant le message de la photographie quant à la variété de ses drapeaux. Le contenu du texte est lui aussi politique, d'ordre militant : " $E$ Tū Ake, Standing strong ». Le propos implicite de l'affiche est que l'exposition concerne un collectif, ancré dans le temps long mais aussi dans la vie contemporaine, avec une culture active et une détermination à l'affirmation politique.

Au musée du quai Branly, l'affiche est centrée sur un objet, un hei tiki tenu dans une main. Le texte donne à lire un premier mot, en caractères grand format, " Māori », et un sous-titre plus petit : "Leurs trésors ont une âme ». L'objet représenté, bien que fortement évocateur de la culture maori, est renvoyé aux collections du musée du quai Branly par le biais d'une petite étoile qui le surplombe - petite étoile qui fait office de "signature » du musée dans tous les supports de communication depuis son ouverture. Le hei tiki ainsi approprié par le musée du quai Branly peut renvoyer à l'idée populaire d'« arts premiers ». Certes la main est une présence humaine, mais fragmentaire et positionnée en arrière-plan. L'impression qui se dégage est que l'exposition est une exposition d'objets. Au plan linguistique, seul le français est utilisé, et l'emploi du terme " leurs » dans le sous-titre insiste sur le fait que le musée du quai Branly accueille et valorise une culture dont il ne se réclame pas. La phrase "Leurs trésors ont une âme " indique une adhésion à la fois à l'idée d'un patrimoine artistique à valeur universelle (" trésors ") et à la conception d'une force active des objets, tout du moins à un caractère sacré - là aussi rabattu sur des valeurs occidentales (via le choix du mot "âme ") $)^{31}$. Se reconnaît "l'esprit » du musée du quai Branly : des objets exceptionnels et mystérieux, signifiant l'altérité.

\footnotetext{
${ }^{31}$ Dans le supplément de Beaux-Arts magazine consacré à l'exposition, l'expression d'« art divin » est employée.
} 
Au musée de la Civilisation du Québec, l'affiche est une photographie grand format d'un visage tatoué maori, et le titre d'origine est conservé et traduit: "E Tū Ake. Māori debout». Pour ce qui concerne l'image, c'est le choix d'un visage qui a été fait, signe d'un retour sur une humanité partagée. La présence du regard s'impose, dans toute son universalité. Mais le tatouage facial, très présent, indique en contrepoint la spécificité d'une culture. Quant au texte, le maintien du contenu original tend à conserver la dimension militante du propos. Le choix des langues - le maori et le français - suggère la cohabitation des langues et des cultures sur un même territoire, voire leur confrontation, renvoyant ainsi à la situation locale, au Québec et au Canada. Ainsi, l'image évoque la tension entre l'universel et le particulier et invite à la découverte de l'inconnu et à la rencontre avec le différent, quand le texte fait ressortir la dimension politique de l'exposition.

\section{Les propos des équipes des musées}

Les propos recueillis lors de nos enquêtes auprès des équipes des différents musées peuvent également être considérés comme du métadiscours institutionnel, d'un autre ordre toutefois, moins officiel, moins cohérent.

Au musée Te Papa Tongarewa, les discours intègrent et défendent le principe de biculturalité. II y a une dimension cumulative des visions du patrimoine au musée : les objets sont conservés et exposés dans le respect des normes internationales soucieuses de leur préservation matérielle ; ils sont dans le même temps maintenus dans une vie culturelle autre que purement muséale, où la préservation de leurs dimensions immatérielles est importante, ainsi que la continuité de leur insertion dans la société qui les porte. Le patrimoine y est considéré comme " vivant » et inséré dans la sphère domestique.

Au musée du quai Branly, les discours des professionnels indiquent une posture d'extériorité. L'exposition est considérée comme "clef en main ". Au sein des propos recueillis, affleure à plusieurs reprises l'idée d'une volonté de contrôle de la part du musée Te Papa Tongarewa :

C'est vraiment une exposition militante d'un peuple qui parle de lui. Donc, c'est entièrement conçu par le musée Te papa. Le parcours, le choix des objets, sont très très cadrés. (...) L'accrochage des objets entre eux, la proximité des objets entre eux, c'était prédéfini. (...) Tous les textes ont été transmis par eux. Ils ont voulu revoir les traductions, l'affiche aussi, l'image de l'affiche. C'est vraiment le propos du Te Papa - en gros, les représentants du peuple māori. II n'y a pas un commissaire ; vraiment, c'est une exposition collégiale, si je puis dire, qui est présentée ici. (Membre de l'équipe du musée du quai Branly).

L'absence de dialogue entre les cultures ressort, avec une certaine ironie, du récit des échanges entre le musée hôte et les équipes du musée concepteur de l'exposition. En outre, le musée Te Papa Tongarewa est assimilé aux Maori - et non considéré comme biculturel. Se dessine ainsi une forme de partage des tâches entre les deux institutions: au musée Te Papa Tongarewa l'affirmation culturelle et politique collective des Maori, au musée du quai Branly la charge institutionnelle de la reconnaissance artistique et de la valorisation des objets présentés. Le musée se positionne comme porte-voix plutôt que porte-parole de la cause māori. 
Au musée de la Civilisation du Québec en revanche, les équipes témoignent d'un sentiment de proximité. L'établissement est vu comme porte-parole de la cause maori, et de la cause autochtone en général - démontrant ainsi une plus grande sensibilité à la problématique autochtone qu'en France, et, du même coup, peutêtre, une moindre attention à la spécificité de la question maori :

\begin{abstract}
Le CAPA, c'est le comité autochtone du musée. C'est eux qui déterminent vraiment quelle ligne on va suivre pour présenter les autochtones, autant dans le propos que dans le côté linguistique et tout... Dans l'exposition, on avait fait affaire avec eux autres, parce que c'est une question : au départ on écrivait Maoris avec un ' $S$ ', puis là on s'est dit, 'hum si le CAPA s'en mêle...' On se demandait: est-ce qu'on traduit?, est-ce qu'on ne traduit pas? Faut-il franciser ou non? C'était toujours une question un peu embêtante, là. (membre de l'équipe du musée de la Civilisation du Québec).
\end{abstract}

Les exigences des Maori quant au traitement des objets sont acceptées comme des revendications culturelles, sans être nécessairement interprétées comme des tentatives de contrôle.

\title{
Conclusion
}

Que ce soit dans le choix des objets, leur mise en scène ou les métadiscours institutionnels portés par les musées qui accueillent l'exposition, se révèle une volonté consciente de mobiliser la notion d'art pour porter un message politique.

Au cours de l'itinérance internationale de l'exposition « $E$ Tū Ake », les valeurs accordées au patrimoine ont été construites, négociées et contestées entre les musées parties prenantes. Le cahier des charges du musée Te Papa Tongarewa imposait un mode de traitement (rituel) des collections, qui entrait en confrontation avec les normes professionnelles en cours dans les musées-hôtes. Mais si l'exposition porte le message d'une affirmation culturelle et politique d'un peuple autochtone qui a choisi de parler pour lui-même, elle s'approprie néanmoins la notion d'art sous ses différentes formes et choisit de recourir à l'instance muséale pour la valoriser. L'exposition joue sur le croisement des regards internes et externes (à la culture Maori) sur la notion d'art, pour s'assurer une validation multiple de la valeur des taonga. Elle s'inscrit ainsi dans une double perspective patrimoniale, à la fois locale et globale : son discours défend l'idée d'une culture vivante, à appréhender avec des concepts autochtones (rapports au passé, au territoire, à la cosmogonie), tout en se déployant dans les sphères artistiques et muséales internationales (conservation du patrimoine, scène de l'art contemporain).

Cette expérience invite l'analyse muséologique elle-même à se " dés-occidentaliser » afin de comprendre les transformations culturelles du patrimoine à l'œuvre dans un monde muséal devenu cosmopolite. Elle engage à «plaider pour un réalisme ethnographique et historique, qui reconnaît la contestation des notions d'histoire et de réalité, l'inventivité de leur traduction dans des lieux tels que les tribunaux, les musées ou les universités » (Clifford, 2013, p. 7, notre traduction). Elle contribue à s'interroger sur la circulation des collections liées aux minorités, sur les usages politiques du patrimoine et sur le rôle de l'institution muséale dans la mise en œuvre d'une interculturalité sud/nord. 


\section{Références}

Bennett, T. (1998). Culture: a Reformer's Science. London: Routledge.

Bennett, T. (2006). " Exhibition, Difference, and the Logic of Culture. " Dans I. Karp, C. A. Kratz, L. Szwaja \& T. Ybarra-Frausto (Eds.), Museum Frictions. Public Cultures/ global Transformations (pp. 46-69). Durham: Duke University Press.

Clifford, J. (1997). Routes, Travel and Translation in the Late Twentieth Century. Cambridge: Harvard University Press.

Clifford, J. (2013). Returns. Becoming indigenous in the Twenty-First century. Cambridge: Harvard University Press.

Crenn, G. (2003). «Rhétorique de la transparence et légitimité muséale : à propos de trois expositions d'ethnologie. » Quaderni, $n^{\circ} 52,93-103$.

Crenn, G. (2012). "L'exposition de la musique populaire au Powerhouse Museum de Sydney. Logiques de production. " Questions de communication, $\mathrm{n}^{\circ} 22,159-180$.

Davallon, J. (2011). « Le pouvoir sémiotique de l'espace. Vers une nouvelle conception de l'exposition ? » Hermès, vol. 3, n61, 38-44.

Debary, O., \& Roustan, M. (2012). (préface de J. Clifford). Voyage au musée du quai Branly. Une anthropologie de la visite du Plateau des collections. Paris: La Documentation française (Musées-Mondes).

Gagné, N., \& Roustan, M. (2014). « Accompagner les taonga à travers le monde : une exposition māori à Paris et à Québec (note de recherche). " Anthropologie et Sociétés, vol. 38, n³, 79-93.

Kreps, C. (2003). Liberating Culture: Cross-Cultural Perspective on Museums, Curation, and Heritage Preservation. London: Routledge.

Kreps, C. (2011). " Non-Western Models of Museums and Curation in CrossCultural Perspective. "In Macdonald, S., (Ed.). A Companion to Museum Studies (pp. 457-472). Chichester: Wiley-Blackwell.

McCarthy, C. (2011). Museums and Māori. Heritage Professionals, Indigenous Collections, Current Practice. Wellington: Te Papa Press.

Onciul, B. (2012). « Rethinking Heritage Community Engagement: Current limitations to power sharing and thoughts for the future." The Re/theorisation of Heritage Studies Conference, Göteborg, Suède, 5-8 juin 2012.

Peers, L., \& Brown, A. (Ed.). (2003). Museums and Source Communities. London: Routledge.

Roustan, M. (2014a). « De l'étude des publics à la recherche sur les musées. Récit d'expériences. " Dans L. Daignault \& B. Schiele (Dir.) Les musées et leurs publics. Savoirs et enjeux. Québec : Les Presses universitaires de Québec.

Roustan, M. (2014b). « De l'adieu aux choses au retour des ancêtres. La remise par la France des têtes māori à la Nouvelle-Zélande. » Socio-anthropologie, $n^{\circ} 30$, pp. 183-198.

Smith, H. (2011a). E Tū Ake. Māori Standing Strong. Wellington: Te Papa Press.

Smith, H. (2011b). Māori - Leurs trésors ont une âme. Paris : Somogy Musée du quai Branly.

Witcomb, A. (2003). Re-imagining the Museum. Beyond the Mausoleum. London : Routledge.

\section{Résumé}

L'exposition «E Tū Ake (Standing Strong) » consacrée aux trésors culturels et aux revendications d'affirmation politique des Maori a été présentée au musée Te Papa Tongarewa (Wellington, NouvelleZélande, 2011), au Musée du Quai Branly (Paris, 2011-2012) et au Musée de la Civilisation du Québec (Québec, 2012-2013). Au cours de l'itinérance internationale de l'exposition, dans des contextes culturels divers, les valeurs accordées au patrimoine ont été construites, négociées et contestées entre les musées parties prenantes. Suivant le principe énoncé par James Clifford pour le musée, c'est l'exposition temporaire itinérante qui devient ici « zone de contact »(Clifford, 1997). A partir de l'analyse des mises en 
exposition et des entretiens menés avec les équipes des musées impliqués, cet article montre comment l'exposition joue sur le croisement des regards internes et externes (à la culture Maori) sur la notion d'art, pour s'assurer une validation multiple de la valeur des taonga et l'inscrire dans une double perspective patrimoniale, à la fois locale et globale. Son discours défend l'idée d'une culture vivante, à appréhender avec des concepts autochtones, tout en se déployant dans les sphères artistiques et muséales internationales. Cette expérience invite l'analyse muséologique elle-même à se " dés-occidentaliser » afin de comprendre les transformations culturelles du patrimoine à l'œuvre dans un monde muséal devenu cosmopolite.

Mots clé : musées d'ethnographie, patrimoine culturel, NouvelleZélande

\section{Abstract}

The "«E Tū Ake» (Standing Strong)" exhibition in Wellington, Paris and Québec. Cultural assertion and heritage policy

The "E Tū Ake (Standing Strong)" exhibition is dedicated to the cultural treasures and the claims of political assertion of the Māori. It was presented at the Museum of New Zealand Te Papa Tongarewa (Wellington, New Zealand, 2011), the Musée du Quai Branly (Paris, 2011-2012) and the Musée de la Civilisation in Quebec (Quebec, 2012-2013). During the international tour in various cultural contexts, the values of heritage were built, negotiated and contested between the different museum stakeholders. Following the principle stated by James Clifford for the museum, it is the traveling exhibition which here becomes a "contact zone" (Clifford, 1997). Through analysis of the exhibition and interviews with museum professionals, this article shows how the exhibition plays on how internal and external viewing of art (from a Māori point of view) cross over to confirm many times over the value of the taonga (treasure/cultural heritage) and enter it in a heritage perspective that is both local and global. It defends the idea of a living culture, understanding it with indigenous concepts, while deploying this culture in international art and museum spheres. This experience calls upon the museum to analyze itself and "deWesternize" in order to understand the transformations of cultural heritage at work in today's cosmopolitan museum world.

Key words: ethnographic museums, cultural heritage, New Zealand 